\title{
Preserving surface area and porosity during fabrication of silicon aerocrystal particles from anodized wafers
}

\author{
C. J. Storey ${ }^{1}$ (1) $\cdot$ E. Nekovic ${ }^{1}$ (D) A. Kaplan ${ }^{1} \cdot$ W. Theis ${ }^{1} \cdot$ L. T. Canham ${ }^{1}$
}

Accepted: 10 October 2020 / Published online: 21 October 2020

(c) The Author(s) 2020

\begin{abstract}
Porous silicon layers on wafers are commonly converted into particles by mechanical milling or ultrasonic fragmentation. The former technique can rapidly generate large batches of microparticles. The latter technique is commonly used for making nanoparticles but processing times are very long and yields, where reported, are often very low. With both processing techniques, the porosity and surface area of the particles generated are often assumed to be similar to those of the parent film. We demonstrate that this is rarely the case, using air-dried high porosity and supercritically dried aerocrystals as examples. We show that whereas ball milling can more quickly generate much higher yields of particles, it is much more damaging to the nanostructures than ultrasonic fragmentation. The latter technique is particularly promising for silicon aerocrystals since processing times are reduced whilst yields are simultaneously raised with ultrahigh porosity structures. Not only that, but very high surface areas $\left(>500 \mathrm{~m}^{2} / \mathrm{g}\right)$ can be completely preserved with ultrasonic fragmentation.
\end{abstract}

Keywords Porous silicon $\cdot$ Ultrasonic fragmentation $\cdot$ Ball milling $\cdot$ Supercritical drying $\cdot$ Comminution $\cdot$ High porosity

\section{Introduction}

Nanostructuring silicon can both tune its properties and endow it with novel properties. One very versatile technique for nanostructuring ultrapure semiconducting silicon is electrochemical etching of wafers [1]. This top-down technique generates crystalline silicon nanostructures with tunable porosity (20-95\%) pore sizes $(1.5-50 \mathrm{~nm})$ and surface areas $\left(100-1125 \mathrm{~m}^{2} / \mathrm{g}\right)$, initially in the form of layers [2]. Many chip-based applications can utilize this physical form. However, microparticles or nanoparticles are needed for a range of in-vivo applications such as biomedical therapy, which exploit the medical biodegradability and very low toxicity of mesoporous silicon [3]. Different methods are available for converting porous silicon ( $\mathrm{pSi}$ ) films to particles such as mechanical milling [4-6] and ultrasonic fragmentation (USF) [7-9]. Particle size reduction via milling can be conducted in a dry or wet environment [6], whereas ultrasonic fragmentation utilises liquid immersion of particles.

C. J. Storey

c.j.storey@bham.ac.uk

1 Nanoscale Physics Research Laboratory, School of Physics \& Astronomy, University of Birmingham, Edgbaston, Birmingham B15 2TT, UK
However, there are outstanding challenges to rapidly generate nanoparticles with good yields and minimal reductions in porosity and surface area. Speed of processing and yields are critical parameters from an industrial perspective in determining the economic viability. Porosity and surface area are crucial technical parameters that can determine the performance. Examples are the porosity determining drug payload and the surface area determining sensor limit of detection. Nevertheless, in most studies concerning USF of pSi [7, 9-14], yields are not provided. Table 1 shows data from two exceptions, together with results from this study. In one prior study [15], pSi nanoparticles of 80-120 nm are obtained from $20 \mu \mathrm{m}$ thick, electrochemically etched p-type membranes. A $24 \mathrm{~h}$ USF process, followed by filtering and centrifugation steps, generated a nanoparticle yield of only $0.2 \%$. By contrast electrochemical etching, employing a perforation etch procedure to create weaker, easily fractured, high porosity regions within the overall porous layer structure have successfully produced a $24 \%$ yield of nanoparticles (150-350 nm in range, " $z$-average" $238 \mathrm{~nm} \pm 5$ ) in combination with a $16 \mathrm{~h}$ USF step, sedimentation and centrifugation [16]. This latter study suggests that USF processing time and yield may be greatly improved by starting with ultrahigh porosity, which also significantly improves payload in drug delivery applications [17]. 
Table 1 Processing times and yield data for generating nanoparticles from pSi membranes

\begin{tabular}{llllll}
\hline References & Etching, drying method & $\begin{array}{l}\text { Layer porosity } \\
(\%)\end{array}$ & $\begin{array}{l}\text { Comminution } \\
\text { method }\end{array}$ & $\begin{array}{l}\text { Comminution time } \\
\text { (minutes) }\end{array}$ & $\begin{array}{l}\text { Particle size (nm) } \\
\text { Yield of } \\
\text { particles } \\
(\%)\end{array}$ \\
\hline Nissinen [6] & PE \& AD & 69 & BM & $2-15$ & $<1000$ \\
Roberts [16] & PE and AD & Not & USF & 960 & $150-350$ \\
This study & SE \& AD & 92 & USF & 240 & $<1000$ \\
This study & SE \& SCD & 85 & BM & 1 & $<1000$ \\
This study & SE and AD & 88 & USF & 30 & $<1000$ \\
Hon [15] & SE and AD & 70 & USF & 1440 & $80-120$ \\
\hline
\end{tabular}

$S E$ standard etching, $P E$ perforation etching, $S C D$ supercritical drying, $A D$ air drying, $B M$ ball milling, $U S F$ ultrasonic fragmentation

Perforation etching used prior to dry ball milling (BM) [6] enabled small particle sizes in the sub-micron range, with reported yields $\sim 100 \%$, and material porosities of around $68 \%$ appear to have largely withstood the aggressive milling forces. Wet ball milling (in water or isopropanol) of non-porous silicon microparticles had shown $97 \%$ yield of submicron particles after $5 \mathrm{~h}$ of processing [18]. However, wet BM has not been utilized extensively with porous silicon feedstocks [19]. Applications which benefit from ultrahigh porosity materials should benefit from more gentle techniques in order to preserve the delicate internal pore structures.

For both BM and USF the resulting particles have a range of morphologies and are not spherical. Typical morphologies for $\mathrm{pSi}$ particles formed via these techniques can be seen from scanning electron microscopy images, such as those in the following studies $[9,12,20]$. Depending on the type of comminution process employed, a significant decrease in overall porosity can result. BM is a fast technique, which is cheap to employ, highly repeatable, but mechanically aggressive and can significantly reduce the porosities of delicate materials. USF is widely used in the preparation of pSi micro and nano-particles, but as far as we are aware, there have been no studies documenting its effect on porosity and surface area in comparison with other techniques. In this study, we have conducted a series of experiments quantifying yields, processing times, and the reduction in both surface areas and porosities for generating sub micron particles by both ball milling and USF. Supercritical drying preserves the porosity of highly porous pSi material [17, 21]. Hence, we have used SCD membranes here as a benchmark of initial porosity, so that comparisons can also be made of damage caused by drying with damage caused by comminution.

\section{Experimental methods}

\subsection{Preparation of porous silicon layers and membranes}

Individual pSi membranes or several membranes (pooled) with similar properties were used in this study. pSi membranes were prepared by the electrochemical etching of heavily boron doped 6 inch crystalline silicon wafers $(0.005-0.02 \Omega \mathrm{cm})$, using a double anodisation cell and a $20 \%$ ethanoic hydrofluoric acid electrolyte. Current densities of between 108 and $130 \mathrm{~mA} \mathrm{~cm}^{-2}$ for $60 \mathrm{~min}$ were applied before electropolishing at an elevated current density (between 165 and $180 \mathrm{~mA} \mathrm{~cm}^{-2}$ ) to detach the membranes from their substrate. Membrane porosities were in the range $65.2 \%$ to $92.3 \%$ and membrane thicknesses varied between 163 and $195 \mu \mathrm{m}$.

\subsection{Drying techniques}

\subsubsection{Air drying (AD) and supercritical drying (SCD)}

After anodisation, the electrolyte was replaced with ethanol which was allowed to evaporate in a Genlab drying cabinet at $50{ }^{\circ} \mathrm{C}$. Supercritical drying (SCD) was conducted directly from ethanol storage, post anodisation, using a Quorum Technologies Ltd K850 critical point drier. Liquid $\mathrm{CO}_{2}$ was used as the exchange fluid, for repeated fill, soak and flush cycles, until all ethanol had been expelled from the system. The chamber was then 
replenished with fresh liquid $\mathrm{CO}_{2}$ and the temperature and pressure increased past the critical point. The super critical fluid was subsequently aspirated slowly from the system to dry the pSi flakes without capillary condensation forces.

\subsection{Comminution techniques}

\subsubsection{Ultrasonic fragmentation (USF)}

Either $0.1 \mathrm{~g}$ or $0.2 \mathrm{~g}$ of pSi membrane flakes were placed in a glass beaker, immersed in $10 \mathrm{ml}$ or $20 \mathrm{ml}$ of ethanol and sonicated with a $30 \mathrm{~W}$, Fisherbrand FB15051 ultrasonic bath for between $30 \mathrm{~min}$ and $4 \mathrm{~h}$.

\subsubsection{Ball milling (BM)}

Between $0.2 \mathrm{~g}$ and $5.8 \mathrm{~g}$ of pSi membrane flakes were dry milled in air using either a $45 \mathrm{ml}$ or $500 \mathrm{ml}$ zirconium oxide grinding bowl and a Fritsch planetary ball miller at $300 \mathrm{rpm}$ for $1 \mathrm{~min}$.

\subsection{Characterisation}

Particle sizing was conducted using ethanol dispersions and laser diffraction in a Malvern Mastersizer 2000, which performs to a particle sizing specification of $0.02-2000 \mu \mathrm{m}$. A small quantity of the surfactant 'Igepal' was added to the sample to form a thick paste prior to sampling and prevent agglomeration. Average measurements were taken from several repeat stable measurements.

Pore characteristics of particles were calculated using a gas adsorption analyser (Micromeritics Tristar 3020). Measurements include: pore volumes calculated by computational analysis of adsorption isotherms via the Barret-Joyner-Halender (BJH) adsorption method; surface area using the adsorption isotherm branch via the Brunauer-Emmett-Teller (BET) method; and pore diameter using the adsorption average. On calibration runs, standard errors for surface area are $\pm 6 \mathrm{~m}^{2} / \mathrm{g}$, pore volume $\pm 0.08 \mathrm{ml} / \mathrm{g}$ and pore diameter $\pm 1.5 \mathrm{~nm}$. Porosity was subsequently calculated from the pore volume and solid volume of silicon utilising the density of silicon $\left(2.33 \mathrm{~g} \mathrm{~cm}^{-3}\right)$.

Membrane thickness was estimated by gravimetric analysis.

\section{Results and discussion}

\subsection{Experiment 1: Ball milling (AD and SCD)}

To determine the effect of BM on different porosity materials, $5.8 \mathrm{~g}$ and $5.1 \mathrm{~g}$ of $\mathrm{SCD}$ and $\mathrm{AD}$ pSi particles respectively (samples UoB 99 and UoB 100), produced from different
Table 2 Particle sizing data of SCD sample (UoB 99) after 1 min BM

\begin{tabular}{lllll}
\hline Sample details & $\mathrm{d}(0.1) \mu \mathrm{m}$ & $\mathrm{d}(0.5) \mu \mathrm{m}$ & $\mathrm{d}(0.9) \mu \mathrm{m}$ & $\begin{array}{l}\text { Yield }<1 \mu \mathrm{m} \\
\text { particles }(\% \\
\text { volume })\end{array}$ \\
\hline $\mathrm{SCD}$ & 2.3 & 21.4 & 82.3 & 4.6 \\
\hline
\end{tabular}

UoBXX values are wafer batch codes representing distinct anodisation runs at the University of Birmingham (UoB). The d value represents particle diameter in microns, and the values shown in the table refer to the cumulative volume of particles below this size as a percentile

Table 3 Degradation in surface area and porosity of SCD (UoB 99) and $\mathrm{AD}$ (UoB 100) samples before and after BM

\begin{tabular}{lllll}
\hline Ball milling & $\begin{array}{l}\text { Surface } \\
\text { area } \\
\left(\mathrm{m}^{2} / \mathrm{g}\right)\end{array}$ & $\begin{array}{l}\text { Pore } \\
\text { volume } \\
\left(\mathrm{cm}^{3} / \mathrm{g}\right)\end{array}$ & $\begin{array}{l}\text { Average pore } \\
\text { diameter }(\mathrm{nm})\end{array}$ & Porosity $(\%)$ \\
\hline $\mathrm{SCD}$ & & & & \\
Before & 400 & 2.4 & 23.0 & 84.9 \\
After & 251 & 1.3 & 19.3 & 74.9 \\
AD & 320 & 0.8 & 10.1 & 65.2 \\
Before & 304 & 0.7 & 9.9 & 63.4 \\
After & 304 & &
\end{tabular}

Membrane thickness $163 \mu \mathrm{m}$ (AD material) 196-206 $\mu \mathrm{m}$ (SCD material)

membranes with different initial porosities, were BM for $1 \mathrm{~min}$. With BM, very rapid particle size reduction can be achieved (Table 2). At $85 \%$ initial porosity about $5 \%$ of particles are already submicron after only 1 min of processing.

However, the extent of damage is revealed in Table 3. Comminution occurs at the cost of a $37 \%$ reduction in surface area and a $46 \%$ reduction in pore volume for SCD material. The reduction in surface area is particularly high, significantly exceeding that of air drying which was only $5 \%$.

\subsection{Experiment 2: Ultrasonic fragmentation (SCD) vs time}

To establish how USF effects high porosity (90\%) material, two $100 \mathrm{mg}$ sub-samples of SCD pSi flakes (UoB 98) were each immersed in $10 \mathrm{ml}$ of $\mathrm{MeOH}$ and sonicated for 1.5 or $4 \mathrm{~h}$ before air drying overnight in a drying cabinet at $50{ }^{\circ} \mathrm{C}$. As a control, a further $100 \mathrm{mg}$ sub-sample was taken from the same SCD sample and immersed in $10 \mathrm{ml} \mathrm{MeOH}$ for $1.5 \mathrm{~h}$ without sonicating and dried as above. All the samples underwent gas adsorption analysis to define pore characteristics and were compared to as received material (Table 4).

Using USF, particle size reduction is considerably slower than BM, however much less damage is incurred. Minimal reduction in surface area has been recorded from the airdried control sample $(<0.5 \%)$ relative to the 'as received' 
Table 4 Pore characteristics of pSi material UoB 98

\begin{tabular}{lllll}
\hline Sample details & $\begin{array}{l}\text { Surface } \\
\text { area } \\
\left(\mathrm{m}^{2} / \mathrm{g}\right)\end{array}$ & $\begin{array}{l}\text { Pore } \\
\text { volume } \\
\left(\mathrm{cm}^{3} / \mathrm{g}\right)\end{array}$ & $\begin{array}{l}\text { Average pore } \\
\text { diameter }(\mathrm{nm})\end{array}$ & Porosity (\%) \\
\hline $\begin{array}{c}\text { As received } \\
\text { material }\end{array}$ & 453 & 3.7 & 32.5 & 89.5 \\
$\begin{array}{l}\text { Control } \\
\text { 1.5 h USF }\end{array}$ & 451 & 2.9 & 26.2 & 87.2 \\
4 h USF & 457 & 2.7 & 23.6 & 86.2 \\
\hline
\end{tabular}

Membrane thickness $182 \mu \mathrm{m}$

Table 5 Particle sizing data of UoB 20

\begin{tabular}{lllll}
\hline Sample details & $\mathrm{d}(0.1) \mu \mathrm{m}$ & $\mathrm{d}(0.5) \mu \mathrm{m}$ & $\mathrm{d}(0.9) \mu \mathrm{m}$ & $\begin{array}{l}\text { Yield }<1 \mu \mathrm{m} \\
\text { particles }(\% \\
\text { volume })\end{array}$
\end{tabular}

\begin{tabular}{lllll}
\hline $\mathrm{USF}+\mathrm{AD}$ & 0.8 & 2.5 & 8.9 & 16.3
\end{tabular}

Table 6 UoB20 — comparison of pore characteristics

\begin{tabular}{lllll}
\hline Sample details & $\begin{array}{l}\text { Surface } \\
\text { area } \\
\left(\mathrm{m}^{2} / \mathrm{g}\right)\end{array}$ & $\begin{array}{l}\text { Pore } \\
\text { volume } \\
\left(\mathrm{cm}^{3} / \mathrm{g}\right)\end{array}$ & $\begin{array}{l}\text { Average pore } \\
\text { diameter }(\mathrm{nm})\end{array}$ & Porosity $(\%)$ \\
\hline $\mathrm{SCD}$ & 549 & 5.1 & 31.3 & 92.3 \\
$\mathrm{AD}$ & 520 & 2.7 & 16.3 & 86.3 \\
$\mathrm{USF}-240 \mathrm{~min}$ & 633 & 1.5 & 8.1 & 77.7 \\
\hline
\end{tabular}

Membrane thickness $195 \mu \mathrm{m}$

material, whilst surface areas of USF samples have actually increased marginally $(0.9 \%$ and $2 \%$ respectively for $1.5 \mathrm{~h}$ and $4 \mathrm{~h}$ sonication times). The act of reducing particle size substantially will slightly increase the outer 'exposed' surface area for a given mass of sample. This is not offset here by the damage/sintering caused.

A significant reduction in pore volume, pore diameter and porosity $(21 \%, 19.4 \%$ and $2.6 \%$, respectively) is seen in the air dried control sample. In contrast, reductions are only marginally elevated after $1.5 \mathrm{~h}$ of USF $(26.4 \%, 27.4 \%$ and $3.7 \%$ ) and virtually no additional damage is seen after $4 \mathrm{~h}$ (26.4\% and $28.9 \%$ and $3.7 \%$ ). Hence, the majority of damage seen here is a result of air drying from the methanol solvent.

Air drying post USF from a low surface tension solvent such as pentane may further reduce damage caused due to air drying and is under investigation.

\subsection{Experiment 3: Ultrasonic fragmentation of aerocrystal (AD vs SCD)}

An ultrahigh porosity (92\%) anodised porous silicon membrane (UoB 20) which had been stored in ethanol without
Table 7 Particle sizing data of UoB 22/23/25

\begin{tabular}{lllll}
\hline Sample details & $\mathrm{d}(0.1) \mu \mathrm{m}$ & $\mathrm{d}(0.5) \mu \mathrm{m}$ & $\mathrm{d}(0.9) \mu \mathrm{m}$ & $\begin{array}{l}\text { Yield }<1 \mu \mathrm{m} \\
\text { particles }(\% \\
\text { volume })\end{array}$ \\
\hline $\mathrm{AD}+\mathrm{BM}$ & 1.2 & 9.8 & 51.9 & 9.3 \\
$\mathrm{USF}+\mathrm{AD}$ & 2.3 & 11.3 & 33.4 & 2.9 \\
\hline
\end{tabular}

Membrane thickness: $190 \mu \mathrm{m}, 187 \mu \mathrm{m}$ and $183 \mu \mathrm{m}$ respectively. Membranes pooled together. Etch parameters 15 A, 60 min

Table 8 Pore characteristics of UoB 22/23/25

\begin{tabular}{lllll}
\hline Sample details & $\begin{array}{l}\text { Surface } \\
\text { area } \\
\left(\mathrm{m}^{2} / \mathrm{g}\right)\end{array}$ & $\begin{array}{l}\text { Pore } \\
\text { volume } \\
\left(\mathrm{cm}^{3} / \mathrm{g}\right)\end{array}$ & $\begin{array}{l}\text { Average pore } \\
\text { diameter }(\mathrm{nm})\end{array}$ & Porosity $(\%)$ \\
\hline $\mathrm{SCD}$ & 560 & 3.1 & 22.4 & 87.8 \\
$\mathrm{AD}$ & 543 & 1.1 & 8.1 & 71.9 \\
$\mathrm{USF}-30 \mathrm{~min}$ & 568 & 1.2 & 8.3 & 73.6 \\
$\mathrm{AD}+\mathrm{BM}$ & 430 & 0.8 & 7.4 & 65.0 \\
\hline
\end{tabular}

prior drying, was divided into three equal subsamples before either supercritically drying, air drying or USF for $4 \mathrm{~h}$ followed by air drying in a drying cabinet. (Table 5 and 6).

For the mechanically weakest, highest porosity (92\%) material we now see a dramatic improvement in the speed of comminution by USF ( $16 \%$ yield of submicron particles within $4 \mathrm{~h}$ ). This compares favourably with the study of Hon [15] (Table 1) where $70 \%$ porosity material required $24 \mathrm{~h}$ of processing for $0.2 \%$ yield of smaller nanoparticles. It also suggests that USF over longer periods (such as $16 \mathrm{~h}$ used in Roberts [16]) would generate yields well above $20 \%$. However, for such aerocrystals, Table 4 suggests that extended USF does seem to slightly lower pore volume compared to the air dried control, whilst surface areas are actually increased. This is under further investigation.

\subsection{Experiment 4: Drying damage vs comminution damage}

For direct comparison of damage caused by drying, as well as USF \& BM techniques, three pSi membranes with similar properties (UoB $22 / 23 / 25-88 \%$ average porosity) were pooled before subdividing into approximate $0.2 \mathrm{~g}$ sample sizes. Sub-samples were either air-dried, supercritically dried, USF for $30 \mathrm{~min}$ in ethanol and then air-dried, or ball milled following air-drying. Particle sizing was also performed. The results are presented in Tables 7 and 8 .

Results show that the higher the initial porosity, the higher the submicron particle yield. This is particularly significant in the ultrahigh porosity range. For example, the BM of UoB 22/23/25 (initial porosity of $88 \%$ ) compared with BM of UoB 99 (85\%) compared favourably with sub-micron 


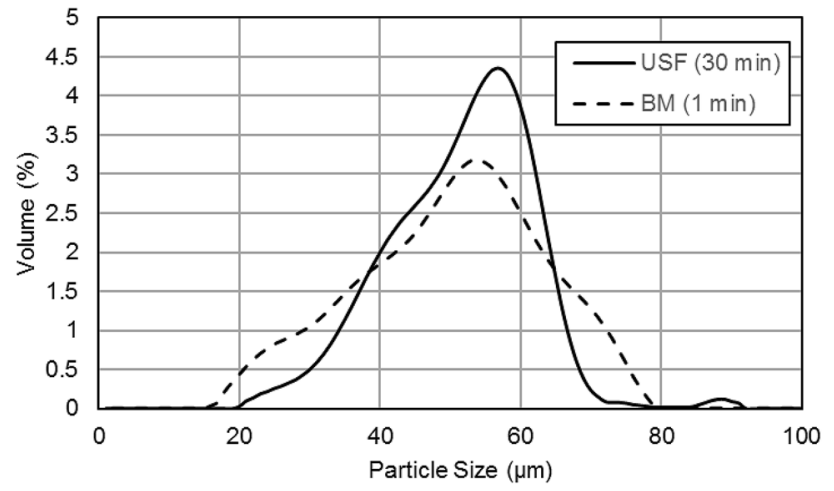

Fig. 1 UoB 22/23/25 particle size distribution after 30 min USF or 1 min BM

yields up to $9 \%$ from $5 \%$. However, this is at the expense of a loss in porosity (23\% drop versus a $10 \%$ drop, respectively), due in turn to a larger proportion of weaker, narrower or more fragile pore walls, which are more susceptible to collapse.

BM for only 1 min contributes a higher submicron particle yield than material sonicated for 30 min with $9 \%$ versus $3 \%$, respectively, as seen in Table 7 . However, the use of thinner membranes (eg. 10-50 $\mu \mathrm{m}$ ) than trialled here $(150-200 \mu \mathrm{m})$ is thought likely to significantly increase yield via USF.

A short 30 min USF showed no deterioration in porosity beyond that caused by air-drying (Table 8). It is proposed that during USF the solvent provides some support to the fragile pore walls, which are thus less prone to damage. Damage incurred at the air-drying stage (equating to reductions of $3 \%$ in surface area, $64 \%$ in pore volume and $64 \%$ in pore diameter below our benchmark SCD values) is due to capillary condensation forces acting upon the delicate pore walls. The destructive nature of BM is reflected in an even greater overall reduction ( $23 \%$ in surface area, $74 \%$ in pore volume and $67 \%$ in pore diameter below benchmark).

Particle sizing data (Table 7 and Fig. 1 displays a narrower size distribution for USF particles compared with BM particles, with a spread of $31 \mu \mathrm{m}$ and $51 \mu \mathrm{m}$, respectively, between the 10th and 90th percentiles of this high porosity material.

\section{Conclusions}

The important studies of Qin [8], Nissinen [6] and Roberts [16] demonstrated that perforation etching can significantly improve the speed of comminution and yields of pSi nanoparticle generation from layers using BM or USF. From data on those parameters alone (Table 1), BM would appear vastly superior to USF. However, a radically different picture emerges when the destructiveness with regard surface area, pore volume and pore size, is quantified before and after processing. We have not utilized perforation etching here because we are primarily interested in exploring the limits of ultrahigh mesopore volume in particles for drug delivery and etching conditions have been optimized to achieve this [17].

We have demonstrated that significant reductions in both pore volume and surface area can often occur with BM. Pore volumes are not greatly affected by USF however and surface areas can actually increase slightly. We have also shown that the yields after defined periods of USF are significantly raised at ultrahigh porosities ( $>85 \%)$. USF would therefore appear particularly attractive for applications that need silicon nanoparticles of very high surface areas $\left(>500 \mathrm{~m}^{2} / \mathrm{g}\right)$ and moderate to high pore volumes. In this regard it is a far superior technique with regard preserving surface area and porosity.

Funding This study was funded by the School of Physics \& Astronomy, University of Birmingham.

Data availability Raw data is available on request.

Open Access This article is licensed under a Creative Commons Attribution 4.0 International License, which permits use, sharing, adaptation, distribution and reproduction in any medium or format, as long as you give appropriate credit to the original author(s) and the source, provide a link to the Creative Commons licence, and indicate if changes were made. The images or other third party material in this article are included in the article's Creative Commons licence, unless indicated otherwise in a credit line to the material. If material is not included in the article's Creative Commons licence and your intended use is not permitted by statutory regulation or exceeds the permitted use, you will need to obtain permission directly from the copyright holder. To view a copy of this licence, visit http://creativecommons.org/licenses/by/4.0/.

\section{References}

1. M.J. Sailor, Porous Silicon in Practice: Preparation. Characterization and Applications (Wiley-VCH Verlag GmbH \& Co. KgaA, Weinheim, 2012)

2. L. Canham, in Handbook of Porous Silicon, 2nd edn., ed. by L. Canham (Springer, Cham, 2018), p. 286

3. H.A. Santos, Porous Silicon for Biomedical Applications, ed. by H.A. Santos. Woodhead Publ. Ser. in Biomater, vol. 68 (2014).

4. L. Russo, F. Colangelo, R. Cioffi, I. Rea, L. De Stefano, Materials 4, 1023-1033 (2011)

5. A. Loni, in Handbook of Porous Silicon. ed. by L. Canham (Springer, Cham, 2014), pp. p1-9

6. T. Nissinen, M. Lama, J. Riikonen, V.-P. Lehto, Powder Technol. 288, 360-365 (2016)

7. J.L. Heinrich, C.L. Curtis, G.M. Credo, M.J. Sailor, K.L. Kavanagh, Science 255, 5040 (1992)

8. Z. Qin, J. Joo, L. Gu, M.J. Sailor, Part. Part. Syst. Charact. 31, 252-256 (2014) 
9. E. Chiste, G. Ischia, M. Scarpa, N. Daldosso, Mater. Res. Express 6, 075006 (2019)

10. A. Troia, A. Giovannozzi, G. Amato, Ultrason. Sonochem. 16, 448-451 (2009)

11. R.A. Bley, S.M. Kauzlarich, J.E. Davis, H.W.H. Lee, Chem. Mater. 8, 1881-1888 (1996)

12. N.H. Maniya, S.R. Patel, Z.V.P. Murthy, Mater. Res. Bull. 57, 6-12 (2014)

13. E. Secret, C. Leonard, S.J. Kelly, A. Uhl, C. Cozzan, J.S. Andrew, Langmuir 32, 1166-1170 (2016)

14. J. Hwang, H. Woo, T. Lee, J. Hong, N. Kim, Y. Choi, Y. Kwon, J. Jang, S. Yoon, T. Paik, J. Choi, J. Ind. Eng. Chem. 82, 197-204 (2020)

15. N.K. Hon, Z. Shaposhnik, E.D. Diebold, F. Tamanoi, B. Jalali, J. Biomed. Mater. Res. Part A 100A, 3416-3421 (2012)

16. D.S. Roberts, D. Estrada, N. Yagi, E.J. Anglin, N.A. Chan, M.J. Sailor, Part. Part. Syst. Charact. 34, 1600326 (2017)
17. E. Nekovic, C.J. Storey, A. Kaplan, W. Theis, L. Canham, ECS J. Sol. State Sci. Technol. 9, 024016 (2020)

18. L.T. Canham, Nanotechnol. 18, 185704 (2007)

19. L.A. Osminkina, M.B. Gongalsky, in Handbook of Porous Silicon, 2nd edn., ed. by L.T. Canham (Springer, Cham, 2018), pp. $227-245$

20. J. Jakubowicz, K. Smardz, L. Smardz, Physica E 38, 139-143 (2007)

21. A. Loni, L.T. Canham, T. Defforge, G. Gautier, ECS J. Solid State Sci. Technol. 4(8), 289-292 (2015)

Publisher's Note Springer Nature remains neutral with regard to jurisdictional claims in published maps and institutional affiliations. 